\title{
Adhesion of the human pathogen Sporothrix schenckii to several extracellular matrix proteins
}

\footnotetext{
O.C. Lima ${ }^{1,3}$,

C.C. Figueiredo ${ }^{1}$,

B.A.S. Pereiral,

M.G.P. Coelho ${ }^{2}$,

V. Morandi ${ }^{1}$ and

L.M. Lopes-Bezerra ${ }^{1}$
}

\author{
Departamentos de ${ }^{1 B i o l o g i a}$ Celular e Genética and \\ 2Bioquímica, Instituto de Biologia Roberto Alcântara Gomes, \\ Universidade do Estado do Rio de Janeiro, Rio de Janeiro, RJ, Brasil \\ ${ }^{3}$ Fundação O swaldo Cruz, FIO CRUZ, Rio de Janeiro, RJ, Brasil
}

\section{Correspondence \\ L.M. Lopes-Bezerra \\ Departamento de Biologia Celular \\ e Genética \\ Instituto de Biologia, UERJ \\ Rua São Francisco Xavier, 524 \\ (PHLC. 205) \\ 20550-900 Rio de Janeiro, RJ \\ Brasil \\ Fax: +55-21-587-7377 \\ E-mail: leila@ uerj.br.}

Presented at the 5th Brazilian Symposium on Extracellular Matrix - SIM EC, Angra dos Reis, RJ, Brasil, September 7-10, 1998.

Research supported by FAPERJ (No. E-26/170.634/96) and CNPq (No. 521443/95-4).

Received December 2, 1998 Accepted January 11, 1999

\section{Abstract}

The pathogenic fungus Sporothrix schenckii is the causative agent of sporotrichosis. This subcutaneous mycosis may disseminate in immunocompromised individuals and also affect several internal organs and tissues, most commonly the bone, joints and lung. Since adhesion is the first step involved with the dissemination of pathogens in the host, we have studied the interaction between S. schenckii and several extracellular matrix (ECM) proteins. The binding of two morphological phases of S. schenckii, yeast cells and conidia, to immobilized type II collagen, laminin, fibronectin, fibrinogen and thrombospondin was investigated. Poly (2-hydroxyethyl methacrylate) (poly-HEMA) was used as the negative control. Cell adhesion was assessed by ELISA with a rabbit anti-S. schenckii antiserum. The results indicate that both morphological phases of this fungus can bind significantly to type II collagen, fibronectin and laminin in comparison to the binding observed with BSA (used as blocking agent). The adhesion rate observed with the ECM proteins (type II collagen, fibronectin and laminin) was statistically significant $(\mathrm{P}<0.05)$ when compared to the adhesion obtained with BSA. No significant binding of conidia was observed to either fibrinogen or thrombospondin, but yeast cells did bind to the fibrinogen. Our results indicate that $S$. schenckii can bind to fibronectin, laminin and type II collagen and also show differences in binding capacity according to the morphological form of the fungus.

\section{Introduction}

Sporotrichosis is a deep mycosis caused by the traumatic implantation of the dimorphic pathogenic fungus, Sporothrix schenckii. This disease has several clinical forms, the most frequent being the cutaneous/subcutaneous one, with associated lymphangitis and

\section{Key words}

- Sporothrix schenckii

- Fibronectin

- Laminin

- Type II collagen

- Adhesion lymph node enlargement (1). Systemic spread may affect the bone, central nervous system and lung, and has been associated mainly with immunocompromised individuals (15 ). These systemic forms of the disease can follow a pulmonary infection by conidia inhalation (6) or dissemination from a cutaneous/subcutaneous lesion (2). Recently, spo- 
rotrichosis has been reported to be an important mycosis in $\mathrm{HIV}^{+}$individuals (5). In these patients, osteoarthritis and the disseminated form of sporotrichosis are frequently observed $(3,4)$.

The dimorphism of $S$. schenckii is determined by temperature. At $37^{\circ} \mathrm{C}$ this fungus differentiates to the yeast form. This morphology is present in cutaneous lesions. The mycelial phase is the saprophytic form of $S$. schenckii and is obtained in vitro by cultivation at $28^{\circ} \mathrm{C}$.

The adherence of a pathogen to host tissues is believed to be an essential step in infectious diseases leading to the dissemination of the microorganism. The most important barriers to be overcome are the endothelium and basement membranes. Little is known about the adhesion and dissemination of pathogenic fungi inside the host. Entactin, fibronectin (FN), laminin, type I collagen and type IV collagen were reported to be involved in the adhesion of some pathogenic fungi to the extracellular matrix (ECM) (7-9). Differences in the binding capacity of Candida albicans were correlated with growth conditions and with the fungal isolate (10). Virulent strains have enhanced binding capacity to fibronectin when compared to avirulent strains (10). An association between binding capacity to ECM proteins and fungus morphological phase was also reported. Conidia of Aspergillus fumigatus bind to fibronectin but the mycelia do not (11). On the other hand, no differences in the ability to bind to entactin were observed between the yeast and hyphal morphologies of Candida albicans (7).

Fungal cell wall components involved in the adhesion process of these pathogens such as cell wall proteins (integrin-like proteins) and mannoproteins were described (12). $S$. schenckii expresses on its cell wall a glycopeptide component, peptido-rhamnomannan (13). This glycopeptide possesses the main antigenic epitopes present on the cell surface of $S$. schenckii and also binds to the lectin Concanavalin A by means of the O-glycosidically linked oligosaccharides $(14,15)$. Differences in cell wall composition of both conidia and yeast cells were observed in $S$. schenckii and are related to the virulence and pathogenesis of this microorganism (16). It is not known whether the cell surface of $S$. schenckii contains adhesins that could mediate host attachment and invasion.

The present investigation is a preliminary study carried out to determine the binding capacity of $S$. schenckii to several extracellular matrix proteins.

\section{Material and Methods}

\section{Material}

Poly (2-hydroxyethyl methacrylate) (polyHEMA), and mouse and human laminin were from Sigma Chemical Co., St. Louis, MO, USA; goat anti-rabbit peroxidase conjugate was from Gibco Life Technologies do Brazil (São Paulo, SP, Brazil); an antiserum against yeast cells of $S$. schenckii was raised in rabbits as previously described (15).

\section{Microorganism and growth conditions}

Sporothrix schenckii strain 1099-18 was used throughout this study. This strain was originally obtained from the Mycology Section, Department of Dermatology, Columbia University, New York, USA. Yeast forms of $S$. schenckii were grown in brain heart infusion broth (BHI, Difco, Detroit, MI, USA) at $37^{\circ} \mathrm{C}$ in rotary shaker (150 rpm). After 7 days in culture the cells were harvested and washed with sterile $50 \mathrm{mM}$ phosphate buffered saline (PBS), pH 7.2. The mycelial phase of $S$. schenckii was grown in Sabouraud broth ( $2 \%$ glucose, $0.5 \%$ yeast extract and $1 \%$ peptone) at $25^{\circ} \mathrm{C}$ for 7 days. Conidia were separated by gauze filtration and washed with sterile PBS. The numbers of yeast cells and conidia were determined with a Neubauer 
chamber. The cell suspension was adjusted to $10^{8}$ cells $/ \mathrm{ml}$.

\section{Isolation of plasma fibronectin and human platelet thrombospondin}

Plasma fibronectin was freshly prepared by gelatin-Sepharose chromatography according to Vuento and Vaheri (17). Thrombospondin (TSP) was obtained from thrombin-activated platelet supernatants as previously described (18). Briefly, supernatants were submitted to heparin-Sepharose chromatography and bound proteins were eluted with growing $\mathrm{NaCl}$ concentrations in the running buffer. The fraction eluted with 0.55 $\mathrm{M} \mathrm{NaCl}$ was concentrated and applied to a Sepharose CL4B column. TSP was eluted in the void volume.

\section{Cartilage collagen purification}

Type II collagen was purified from xiphoid cartilage of chicks by a modification of the method of Trenthan et al. (19). The cartilage was pulverized with liquid nitrogen and incubated with 20 volumes (w/v) of a 50 $\mathrm{mM}$ Tris/ $2 \mathrm{M} \mathrm{MgCl}_{2}$ solution, $\mathrm{pH} 7.4$, at $4^{\circ} \mathrm{C}$ for $18 \mathrm{~h}$ with constant shaking. The extract was then centrifuged at $25,000 \mathrm{~g}$ for $15 \mathrm{~min}$ and the precipitate was washed 3 times with distilled water. The residue was then suspended in 3 volumes of $0.5 \mathrm{M}$ acetic acid and the $\mathrm{pH}$ was adjusted to 2.5 with formic acid. Pepsin was added to the suspension $(1 \mathrm{~g} / 30 \mathrm{~g}$ cartilage) followed by incubation at $4{ }^{\circ} \mathrm{C}$ for $48 \mathrm{~h}$, with constant gentle shaking. After this period, the undigested residue was separated by centrifugation at $25,000 \mathrm{~g}$ for $15 \mathrm{~min}$ and washed 3 times with $0.5 \mathrm{M}$ acetic acid under the same conditions. The supernatants from the extraction and washes were pooled and dialyzed twice, first against distilled water for $12 \mathrm{~h}$ and then against $50 \mathrm{mM}$ Tris/ $/ 0.2 \mathrm{M}$ $\mathrm{NaCl}, \mathrm{pH} 7.6$, for $24 \mathrm{~h}$, followed by centrifugation. The extract was diluted 5-fold in dialysis buffer and then passed through a
DEAE-cellulose column previously equilibrated with the same buffer. Non-binding protein (collagen) was eluted and precipitated by the addition of $\mathrm{NaCl}$ to a final concentration of $3 \mathrm{M}$. After centrifugation at $20,000 \mathrm{~g}$ for $10 \mathrm{~min}$, the precipitate was dissolved in $0.5 \mathrm{M}$ acetic acid and exhaustively dialyzed against $10 \mathrm{mM} \mathrm{Na} 2 \mathrm{HPO}_{4}$. The precipitate isolated by centrifugation was dissolved in acetic acid and then submitted to another precipitation with $1 \mathrm{M} \mathrm{NaCl}$. Finally, the collagen was solubilized and dialyzed against acetic acid at $4{ }^{\circ} \mathrm{C}$ and lyophilized.

\section{Polyacrylamide gel electrophoresis}

Purity of type II collagen, FN and TSP preparations was characterized by SDS-polyacrylamide gel discontinuous electrophoresis (SDS-PAGE) using the method of Laem$\mathrm{mli}(20)$. The proteins were silver stained by the method of Morrissey (21).

\section{ELISA}

The adhesion of $S$. schenckii cells to the ECM proteins was evaluated by ELISA with the immobilized proteins. Wells of polystyrene microtiter plates (Maxisorp, Nunc, Roskilde, Denmark) were coated with 100 $\mu 1$ of TSP, FN, laminin, fibrinogen or type II collagen (CII) $(10 \mu \mathrm{g} / \mathrm{ml}$ in $0.2 \mathrm{M}$ bicarbonate buffer, $\mathrm{pH}$ 9.4) by passive adsorption overnight at $4{ }^{\circ} \mathrm{C}$. The plates were then washed with PBS containing $0.05 \%$ Tween 20 (PBSTween). Non-specific binding was blocked by incubating the plates for $2 \mathrm{~h}$ at $37^{\circ} \mathrm{C}$ with $1 \%$ BSA in $50 \mathrm{mM}$ PBS, $\mathrm{pH}$ 7.4. After a further PBS-Tween washing step, $10^{7}$ yeast cells or conidia were added per well followed by incubation for $1 \mathrm{~h}$ at $37^{\circ} \mathrm{C}$. The plates were then washed in order to remove unbound cells and $100 \mu \mathrm{l}$ of a rabbit anti-S. schenckii antiserum (1:500) was added to each well. The plates were incubated for $1 \mathrm{~h}$ at $37^{\circ} \mathrm{C}$, washed and then incubated with a 
Figure 1 - Adhesion of S. schenckii yeast cells $(A)$ and conidia $(B)$ to immobilized fibronectin, thrombospondin and fibrinogen at $10 \mu \mathrm{g} / \mathrm{ml}$ compared to adhetracted from the negative control (poly-HEMA). S. schenckii adhesion ( $10^{7}$ cells/well) was assessed by ELISA with an anti-S. compared to BSA (Student t-test) sion to BSA. Values were subschenckii antiserum $* \mathrm{P}<0.05$

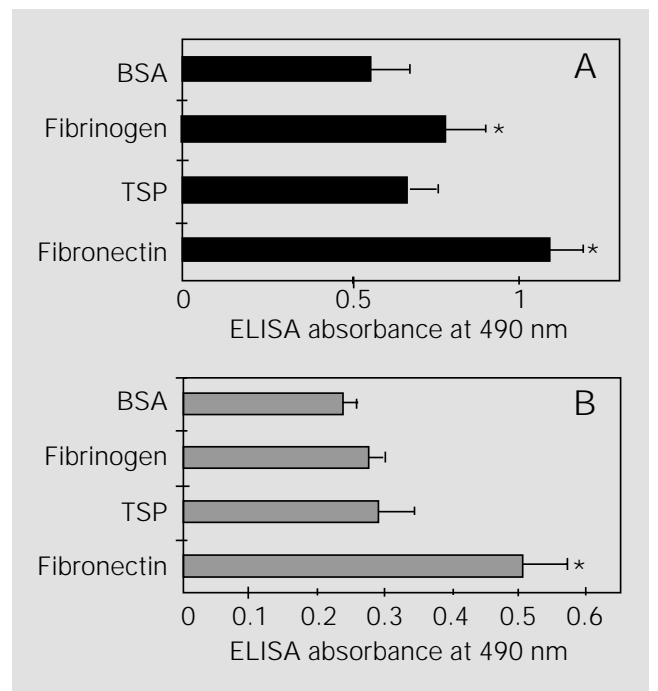

Figure 2 - Binding of S. schenckii conidia (gray bars) and yeast cells (black bars) to immobilized murine and human laminins at $10 \mu \mathrm{g} / \mathrm{ml}$ compared to adhesion to BSA. Values were subtracted from the negative control (polyHEMA). S. schenckii adhesion ( $10^{7}$ cells/well) was assessed by ELISA with an anti-S. schenckii antiserum. $* P<0.05$ compared to BSA (Student t-test).

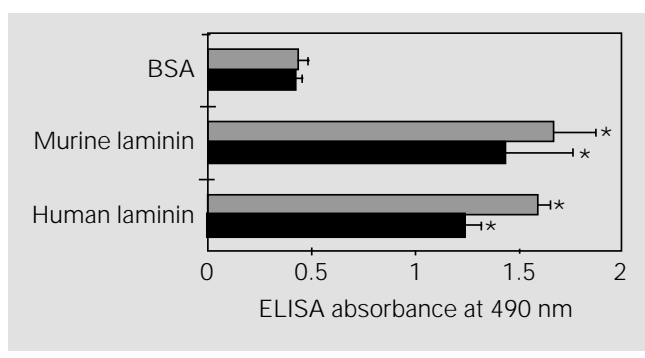

goat anti-rabbit IgG peroxidase-linked conjugate (1:4000 in PBS-Tween). The plates were washed with PBS-Tween and the reaction was developed with the substrate $o$-phenylenediamine (OPD) $(0.5 \mathrm{mg} /$ $\mathrm{ml}$ and $0.005 \% \mathrm{H}_{2} \mathrm{O}_{2}$ in $0.01 \mathrm{M}$ sodium citrate buffer, $\mathrm{pH}$ 5.6). The reaction was stopped after 5 min with $0.2 \mathrm{M} \mathrm{H}_{2} \mathrm{SO}_{4}$, and the $\mathrm{A}_{490}$ was measured using an automated reader (BioRad ELISA Reader, Hercules, CA, USA). Each experiment was done in triplicate and the results correspond to a typical experiment from at least three independent repeats.

\section{Adhesion index}

The differential binding capacity between the yeast phase and conidia of $S$. schenckii was determined by the application of the formula presented below, in order to estab- lish the relative adhesion index for $\mathrm{FN}$ and laminin: $\mathrm{A}_{490} \mathrm{ECM}$ protein $/ \mathrm{A}_{490} \mathrm{BSA}-\mathrm{A}_{490}$ poly-HEMA

\section{Statistical analysis}

Values are reported as mean \pm standard deviation. The unpaired Student $t$-test was used to compare differences between the binding capacity to extracellular matrix proteins and the binding to BSA, as well as to determine differences associated with the morphological phase of the fungus. $\mathrm{P}<0.05$ was considered significant.

\section{Results}

\section{Adhesion of S. schenckii to FN, TSP and fibrinogen}

In order to evaluate the adhesion of $S$. schenckii yeast cells and conidia to the extracellular matrix proteins, fibronectin, thrombospondin and collagen, these proteins were immobilized on ELISA plates and incubated with $10^{7}$ cells of each morphological phase of this fungus. The binding was measured as described in Methods and expressed by the absorbance at $490 \mathrm{~nm}$. Figure 1 (A and B) represents a typical experiment from at least three independent experiments. As observed in Figure 1, both morphological phases significantly bound to fibronectin, as compared to the binding observed with $\mathrm{BSA}(\mathrm{P}<0.05)$. No significant adhesion was observed for conidia assayed with TSP or fibrinogen (Figure 1B). On the other hand, S. schenckii yeast cells showed a significant extent of adhesion to fibrinogen $(\mathrm{P}<0.05)$ but not to TSP (Figure 1A).

\section{Adhesion of S. schenckii to murine and human laminin}

Both the yeast phase and conidia of $S$. schenckii bound to laminin from different sources (Figure 2). No differences were ob- 
served in the rate of adhesion to human and murine laminins.

\section{Comparison of the adhesion index for laminin and FN}

Since the absolute adhesion rates varied between experiments, although adhesion to fibronectin and laminin was always significant, we determined the relative adhesion index as described in Methods. Figure 3 shows that the adhesion rate to laminin and FN is almost similar. However, differences according to the fungal morphological phase were observed only for FN.

\section{Binding of S. schenckii to type II collagen}

Type II collagen was purified as described in Methods. The purification of chick type II collagen by this procedure yielded $35.5 \pm 16$ $\mathrm{mg} \mathrm{CII} / \mathrm{g}$ cartilage. The degree of purification of the CII preparation was evaluated by SDS-PAGE (Figure 4). A main $156-\mathrm{kDa}$ protein band corresponding to the alpha chains of chick type II collagen was observed. The purified CII showed a high degree of purity in comparison to the commercial patterns. S. schenckii conidia and yeast cells were able to significantly attach to type II collagen (Figure 5). Conidia displayed an increased adhesion to CII compared to yeast cells ( $\mathrm{P}<0.05)$.

\section{Discussion}

Sporotrichosis is a deep mycosis which may evolve to a systemic pathology in immunocompromised individuals. The yeast phase of $S$. schenckii is the morphology present in lesions and is thought to disseminate in the systemic disease. However, mycelial elements have already been described in histopathological specimens of lung from sporotrichosis patients (22). Conidia are also thought to infect humans by inhalation (6).

Primary adhesion of endothelial and/or

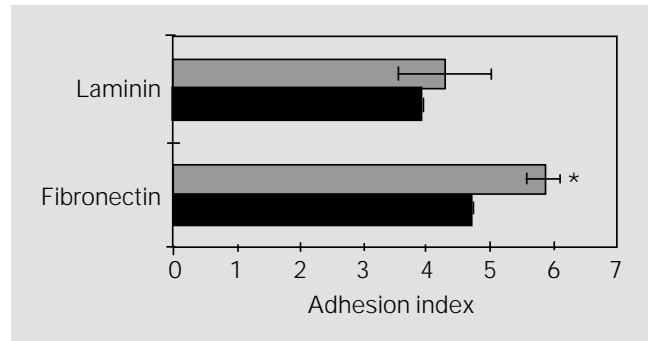

Figure 3 - Relative adhesion index of S. schenckii yeast phase (black bars) and conidia (gray bars) to immobilized fibronectin and laminin. The adhesion index was calculated using the formula: $\mathrm{A}_{490}$ to $\mathrm{ECM}$ protein/ $\mathrm{A}_{490}$ to BSA - $\mathrm{A}_{490}$ with poly-HEMA (negative control). S. schenckii binding ( $10^{7}$ cells/well) was assessed by ELISA with an anti-S. schenckii antiserum. $* \mathrm{P}<0.05$ compared to yeast cells (Student t-test).

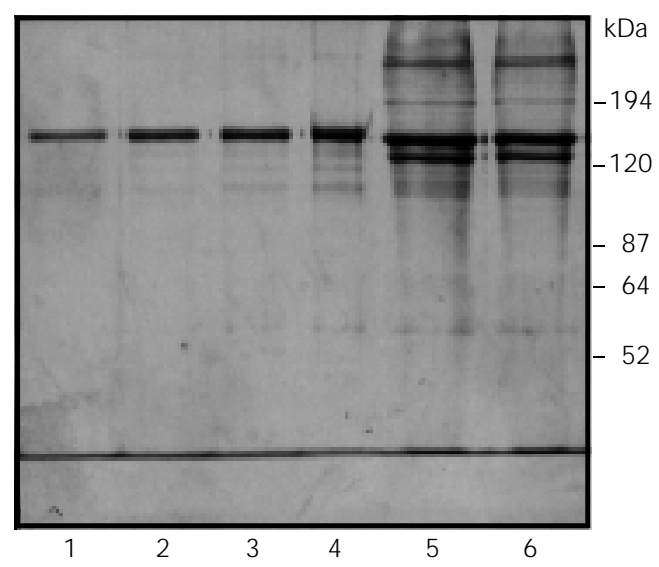

Figure 4 - Analysis of chick type II collagen by $7 \%$ SDS-polyacrylamide gel electrophoresis, with silver staining. Chicken Cll: lane 1, 14 ng; lane 2, 20 ng; lane 3, $30 \mathrm{ng}$; lane 4, $60 \mathrm{ng}$ and type VII collagen (Sigma); lane 5, $50 \mathrm{ng}$, and lane 6, $100 \mathrm{ng}$.

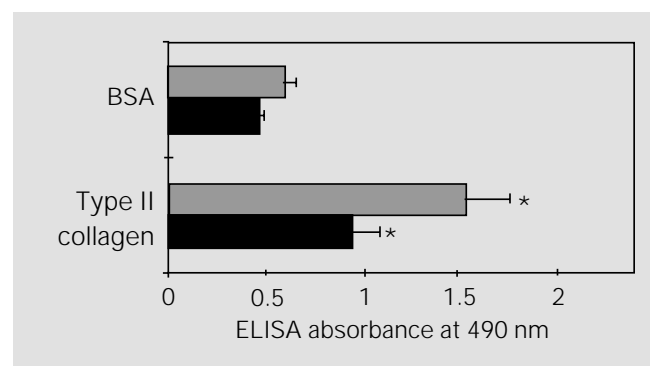

epithelial cells, as well as extracellular matrix components seem to be essential for successful host invasion by pathogens. In the present report we have investigated the binding capacity of two infective forms of $S$. schenckii (yeast form and conidia) to FN, laminin, type II collagen, TSP and fibrinogen. The binding to BSA observed here has already been described for other pathogenic fungi such as Candida albicans (23).

Our results show that $S$. schenckii cells can recognize three important ECM glycoproteins: fibronectin, laminin and type II
Figure 5 - Binding of S. schenckii conidia (gray bars) and yeast cells (black bars) to immobilized type II collagen at $10 \mu \mathrm{g} / \mathrm{ml}$ in comparison with the adhesion observed to BSA. Values were subtracted from the negative control (poly-HEMA). S. schenckii adhesion ( $10^{7}$ cells/well) was assessed by ELISA with an anti-S. schenckii antiserum. $* \mathrm{P}<0.05$ compared to BSA (Student t-test). 
collagen. ECM-binding adhesins have been described for several microorganisms, including bacteria, protozoa and fungi. Most common adhesins recognize fibronectin and collagenous proteins (24). Type II collagen is present in hyaline cartilage, as well as in vitreous humor (25). In immunocompromised individuals, mainly in $\mathrm{HIV}^{+}$patients and alcoholics, the pulmonary and articular forms of sporotrichosis are the most frequent clinical manifestations $(5,26)$. This fungus was also recently isolated from aqueous humor (27). Since this apparent tropism of $S$. schenckii may be associated with the ability to recognize specific ECM components, we investigated binding of this pathogen to type II collagen. Our results showed that conidia and, less markedly, yeast cells bind to type II collagen significantly more than to BSA. Interestingly, $S$. schenckii cells bound only slightly to type I and III collagens (data not shown). Fibronectin is a ubiquitous glycoprotein found in high concentrations in the extracellular matrix and body fluid of vertebrates. Binding to fibronectin may play a role in the invading ability of microorganisms.

In the present study, $S$. schenckii cells strongly recognized laminin from different sources. Laminin is a major component of basement membranes, which, together with endothelial and epithelial monolayers, constitute the main physiological barriers to be surmounted by invading organisms. However, data concerning the involvement of laminin as a target of fungal adhesins are scarce. It has been suggested that the ability to bind basement membrane components is correlated with high virulence phenotypes. Vicentini et al. (28) have reported that the 43-kDa antigen binds to laminin, which leads to the enhancement of Paracoccidioides brasiliensis pathogenesis, by means of laminin recognition. Whether the laminin-binding capacity of $S$. schenckii is critical for the onset of systemic infections remains to be established.

Taken together, our data suggest that $S$. schenckii presents an adhesive behavior comparable to that of other opportunistic pathogens, since it is able to bind both to the basement membrane and to connective ECM proteins. Indeed, this is supported by the fact that this fungus also interacts with specific molecules on human endothelial cells in vitro (Figueiredo CC, Lima OC, Lopes-Bezerra LM and Morandi V, unpublished data).

The present report contributes new data to the understanding of the pathogenesis of sporotrichosis. The identification of S. schenckii cell surface adhesin(s), as already described for other pathogenic fungi $(12,29)$, constitutes a future challenge that could lead to new antifungal therapies.

\section{Acknowledgments}

The authors acknowledge the skillful technical assistance of Mr. Heclair Rodrigues Pimentel Filho and Mrs. Maria Cristina da Costa e Silva.

\section{References}

1. Travassos LR (1985). Sporothrix schenckii. In: Szaniszlo PJ (Editor), Fungal Dimorphism, with Emphasis on Fungi Pathogenic for Humans. Plenum Press, New York.

2. Castrejón OV, Robles $M \&$ Arroyo OEZ (1995). Fatal fungemia due to Sporothrix schenckii. Mycoses, 38: 373-376.

3. Heller HM \& Fuhrer J (1991). Disseminated sporotrichosis in patients with
AIDS: case report and review of the literature. AIDS, 5: 1243-1246.

4. Durden FM \& Elewski B (1997). Fungal infections in HIV-infected patients. Seminars in Cutaneous Medicine and Surgery, 16: 200-212.

5. Howell SJ \& Toohey J S (1998). Sporotrichal arthritis in south central Kansas. Clinical Orthopedic, 346: 207-214.

6. Farley ML, Fagan MF, Mabry LC \&
Wallace RJ (1991). Presentation of Sporothrix schenckii in pulmonary cytology specimens. Acta Cytologica, 35: 389395.

7. López-Ribot J L \& Chaffin WLJ (1994). Binding of extracellular matrix component entactin to Candida albicans. Infection and Immunity, 62: 4564-4571.

8. Klotz AS \& Smith RL (1995). Gelatin fragments block adherence of Candida albi- 
cans to extracellular matrix proteins. Microbiology, 141: 2681-2684.

9. Gil $M L$, Peñalter $M C$, Lopez-Ribot J L, O'Connor J E \& Martinez J P (1996). Binding of extracellular matrix proteins to Aspergillus fumigatus conidia. Infection and Immunity, 64: 5239-5247.

10. Nègret $E$, Vogel $T$, Levanon $A$, Guy $R$, Walsh TJ \& Roberts DD (1994). The collagen binding domain of fibronectin contains a high affinity binding site for Candida albicans. J ournal of Biological Chemistry, 269: 22039-22045.

11. Peñalter MC, O'Connor J E, Martinez J P \& Gil ML (1996). Binding of human fibronectin to Aspergillus fumigatus conidia. Infection and Immunity, 64: 1146-1153.

12. Hostetter MK (1996). Adherence molecules in pathogenic fungi. Current Opinion in Infectious Diseases, 9: 141-145.

13. Lloyd KO \& Bittoon MA (1971). Isolation and purification of a peptido-rhamnomannan from the yeast form of Sporothrix schenckii. Structural and immunochemical studies. J ournal of Immunology, 107: 663-671.

14. Lopes LM, Mendonça-Previato L, Fournet B, Degand P \& Previato J O (1992). Oglycosidically linked oligosaccharides from peptidorhamnomannans of Sporothrix schenckii. Glycoconjugate J ournal, 9: 7581.

15. Lopes LM, Travassos LR, Previato J O \& Mendonça-Previato L (1994). Novel antigenic determinants from peptidorhamnomannans of Sporothrix schenckii. Gly- cobiology, 4: 281-288.

16. Fernandes KSS (1998). Estudo da virulência do patógeno humano Sporothrix schenckii em modelo murino in vivo e in vitro. Master's thesis, Universidade do Estado do Rio de J aneiro, Rio de J aneiro, Brasil.

17. Vuento $M \&$ \&aheri A (1979). Purification of fibronectin from human plasma by affinity chromatography under nondenaturating conditions. Biochemical J ournal, 183: 331-337.

18. Dubernard V \& Legrand C (1991). Characterization of the binding of thrombospondin to human platelets and its association with the platelet cytoskeleton. J ournal of Laboratory and Clinical Medicine, 118: 446-457.

19. Trenthan DE, Townes AS \& Kang AH (1977). Autoimmunity to type II collagen: an experimental model of arthritis. J ournal of Experimental Medicine, 146: 857868.

20. Laemmli UK (1970). Cleavage of structural proteins during the assembly of the head of bacteriophage T4. Nature, 227: 680-685.

21. Morrissey J H (1981). Silver stain for proteins in polyacrylamide gels: A modified procedure with enhanced uniform sensitivity. Analytical Biochemistry, 117: 307310.

22. Gori S, Lupetti A, Moscato G, Parenti M \& Lofaro A (1997). Pulmonary sporotrichosis with hyphae in a human immunodeficiency virus-infected patient. A case re- port. Acta Cytologica, 41: 519-521.

23. Santoni G, Gismondi A, Liu J H, Punturieri A, Santoni A, Frati L, Piccoli M \& Djeu J Y (1994). Candida albicans expresses a fibronectin receptor antigenically related to $\alpha 5 ß 1$ integrin. Microbiology, 140: 2971 2979.

24. Patti J M \& Höök M (1994). Microbial adhesins recognizing extracellular matrix macromolecules. Current Opinion in Cell Biology, 6: 752-758.

25. Rest MVD \& Garrone R (1991). Collagen family of proteins. FASEB J ournal, 5 : 2814-2823.

26. Kauffman CA, Pappas PG, McKinsey DS, Grenfield RA, Perfect J R, Cloud GA, Thomas CJ \& Dismukes WE (1996). Treatment of lymphocutaneous and visceral sporotrichosis with fluconazole. Clinical Infectious Diseases, 22: 46-50.

27. Vieira Dias $D$, Sena $C M$, Oréfice $F$, Tanure MA \& Hamdan J S (1997). Ocular and concomitant cutaneous sporotrichosis. Mycoses, 40: 5-6.

28. Vicentini AP, Geszetesi J L, Franco MF, Souza W, Moraes J Z, Travassos LR \& Lopes JD (1994). Binding of Paracoccidioides brasiliensis to laminin through surface glycoprotein gp43 leads to enhancement of fungal pathogenesis. Infection and Immunity, 62: 1465-1469.

29. Kanbe T \& Cutler J E (1994). Evidence for adhesin activity in the acid-stable moiety of the phosphomannoprotein cell wall complex of Candida albicans. Infection and Immunity, 62: 1662-1668. 